\title{
Using the Irrigation Controller for a Better Lawn on Less Water 1
}

Jack Tichenor, Michael D. Dukes, and L.E. Trenholm²

\section{Introduction}

Would you like to have an attractive, healthy lawn that uses less water, costs less to maintain and may even reduce fertilizer and pesticide use? This may sound too good to be true. The right amount of water at the right time can make it happen for you.

If you have an automatic irrigation system at your home or business, the "brain" of your system is the controller (Figure 1) that hangs on the garage or utility room wall and tells the sprinkler system when and how long to operate. Since there isn't enough water supply to irrigate a lawn all at once, an automatic underground irrigation system breaks the job down into smaller areas called zones. Usually there are 4 or more zones, depending upon the size of the lawn. The water to each zone goes through its own electrically operated valve, with a buried "signal" wire going from the irrigation controller to each valve.

While automation is becoming increasingly necessary in our lives, improper operation of

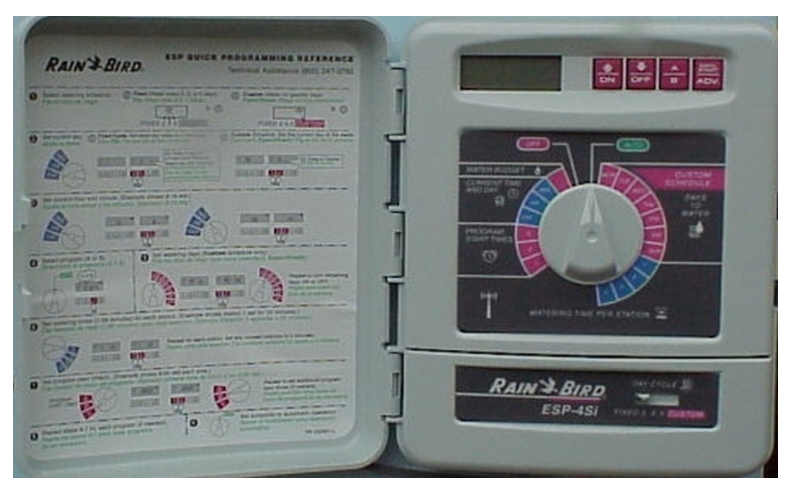

Figure 1. Automatic Irrigation Controller

automatic sprinkler systems is one of the biggest factors leading to the decline of home lawns and the waste of water. Our well-meaning efforts to have a beautiful, lush lawn have driven some of us to apply large amounts of water, fertilizer and pesticides. However, this results in additional mowing and may actually increase diseases, insects, weeds, and environmental stresses. It also depletes natural resources and may increase leaching of fertilizer into ground or surface water. Also, many people don't have an understanding and just guess at the controller settings. The solution?

1. This document is Fact Sheet ENH978, one of a series of the Environmental Horticulture department, Florida Cooperative Extension Service, Institute of Food and Agricultural Sciences, University of Florida. Original publication date: December 23, 2003. Reviewed November 2004. Please visit the EDIS website at http://edis.ifas.ufl.edu

2. Jack Tichenor, Extension Agent II, Institute of Food and Agricultural Sciences, University of Florida, Manatee County Extension Service, Palmetto, FL 34221; Michael D. Dukes, Assistant Professor, Agricultural and Biological Engineering Department, Institute of Food and Agricultural Sciences, University of Florida, Gainesville, FL 32611; L.E. Trenholm, Assistant Professor, Institute of Food and Agricultural Sciences, University of Florida, Environmental Horticulture Department, Gainesville, FL 32611.

The Institute of Food and Agricultural Sciences (IFAS) is an Equal Opportunity Institution authorized to provide research, educational information and other services only to individuals and institutions that function with non-discrimination with respect to race, creed, color, religion, age, disability, sex, sexual orientation, marital status, national origin, political opinions or affiliations. U.S. Department of Agriculture, Cooperative Extension Service, University of Florida, IFAS, Florida A. \& M. University Cooperative Extension Program, and Boards of County Commissioners Cooperating. Larry Arrington, Dean 
On established lawns, water on an as needed basis, not on a fixed schedule. The key to watering as needed is in taking control of your irrigation controller. It's not a "set and forget" thing.

\section{Proper Controller Set Up}

The controller may be the brain of the system, but it only knows what it has been told to do. Newer controllers are easier to set, usually with simple instructions on an attached label, so look there for details on your model. What we're going to do is learn what information to put into the irrigation controller to put you in control.

After setting the current day and time, there are basically only three things the controller needs to be told:

\section{- What $\operatorname{day}(s)$ to water}

\section{- What time to begin}

\section{- How long each zone should run}

After the initial setup of the controller, only the first (what day to water) needs to be adjusted for changes in rainfall patterns and seasons to keep your lawn at its best without overwatering or underwatering. Only change when to water: not how long. Let's look at these three settings.

\section{What Day(s) to Water}

Legally, your Water Management District (WMD), (there are five districts in Florida) and local ordinances regulate which day(s) of the week you are allowed to water, depending on your address. This schedule may be in the local newspaper, or you can contact your WMD or local water utility department for specifics. Don't make the mistake of watering every day allowed just because you can! There are many months when your lawn will need much less water than is allowed. Remember: water only as needed. Here's how: let your lawn tell you when it needs water. Water grass only after about $30 \%$ of your lawn starts to wilt. Signs of wilting include footprints that remain in the grass long after being made, a bluish-gray appearance to the lawn, and a large portion of leaf blades that are folded in half length-wise (Figure 2).

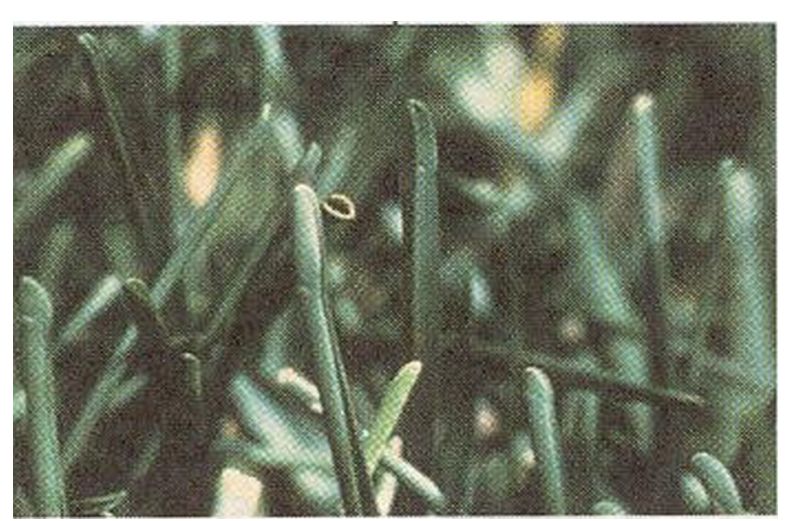

Figure 2. Folded Grass Leaf Blades-Dry

When leaves of flowers, annuals and shrubs begin showing signs of drooping or wilting, it's time to schedule water for them. Watering this way encourages plant roots to grow downward where there is a deeper reservoir of moisture to draw from. If you have been watering frequently and lightly, it may take several weeks or longer for your plants to develop deeper roots. Drought tolerance will be improved while some diseases and weeds are reduced. How often you irrigate will depend upon your location, the current rainfall status, the season, your soil type, plants (drought tolerant vs. thirsty), and the amount of sun exposure. However, as a general guideline, Florida lawns with typical landscaping need water only every 3 to 5 days in the spring and summer and every 10 to 14 days or longer in the winter. Work with nature: irrigate only when rainfall doesn't replenish the dry root zone.

For optimum water efficiency, set the irrigation controller for "automatic" operation only when irrigation is needed. That's when you have determined that the soil moisture is depleted and no rain is expected or for times when you will be away from home. Otherwise, leave the controller in the "off" position. The setting for "what day(s)" must be on your allowed watering day(s) so when you switch the controller to automatic, watering will occur on a legal day. In deciding when to water again, anticipate additional drying while waiting for your next allowed watering day.

A rain gauge is a simple yet helpful tool to use when deciding when to water. If $1 / 2$ inch or more rain has recently fallen, empty the gauge, leave your controller off and delay the next watering. 


\section{Low Volume or Micro-Irrigation}

Low volume or micro-irrigation on shrubs or flowers typically operates on a schedule different from rotor and spray sprinkler schedules. That's why when you use micro-irrigation, you need a controller with "dual programming" capabilities. It's like having two controllers in one - so the micro zone(s) can be on their own schedule independent of the lawn zones using spray and rotor type sprinklers.

Determining a watering schedule for micro-irrigation zones is unique to each installation. Try this. Water until the root zone is moist. This may take some time, as some micro-irrigation systems apply water at slower rates than other lawn sprinklers. Then wait until the soil is dry, or wilting begins, before repeating. This may be a shorter time than for a zone with lawn sprinklers. Fine tune from this to determine how often and how long to water each micro-irrigation zone. Historically, the WMDs have recognized the water-saving potential and unique scheduling requirements of micro-irrigation and have exempted it from some watering restrictions.

However, since micro-irrigation is out of sight, be careful not to leave it on too long and over water.

\section{What Time to Begin?}

Water evaporation loss from sprinklers is greatest during the middle of the day due to the stronger sunlight and increased winds, so the WMDs restrict watering during the midday hours. Statewide, irrigation is prohibited between the hours of 10:00 am and 4:00 pm. The restricted times for a specific area may vary slightly within WMDs or locally, so check with authorities as you did above for what days to water. Water during the cool, calm morning hours to minimize evaporation loss and sprinkler pattern disruption. Watering in the early morning also reduces the time plants are wet, which reduces disease.

\section{How Long Should Each Zone Run?}

Most Florida soils typically hold about 3/4 inch of water in the top 8 to 9 inches of soil, which is the normal rooting depth of most lawn and landscape plants (Figure 3).

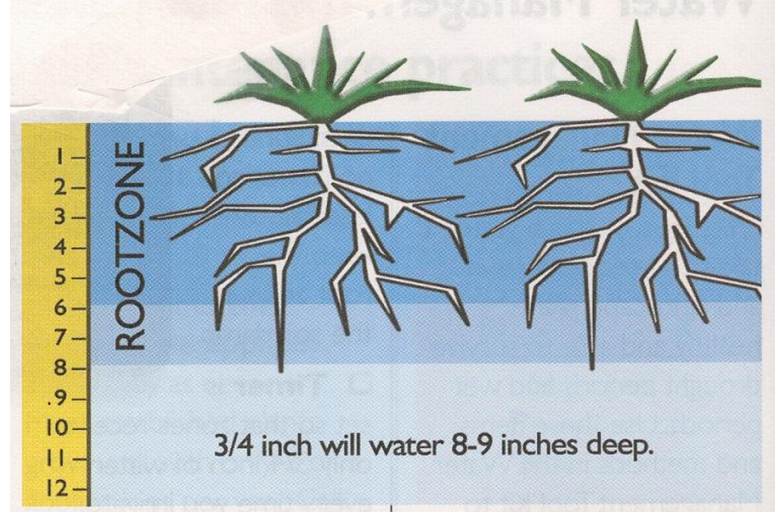

Figure 3. Determining how long to water.

Your goal is to refill that soil moisture reservoir when it becomes depleted and no rain is expected. Each irrigation zone is unique and the run time for each is determined separately. You want the controller to run long enough to put $3 / 4$ inch of water on each zone. Controller settings are in minutes, not inches of water, so how do you go from 3/4 inch of water to minutes of run time for each zone? The answer is to calibrate the irrigation system, zone by zone.

Here's how. On your watering day, randomly place 5 to 7 empty, straight-sided, open-top cans in zone 1 and operate the zone until 3/4 inch water is collected in the cans. Note the time it took to collect an average of 3/4 inch of water in the cans. Set that number of minutes in the controller for zone 1. Repeat the calibration process for each remaining zone. Later observation of drying patterns may indicate the need to adjust the time upward for hot, sunny zones or downward for shady zones. Write down the zone times for future reference in case the controller's memory should fail. Replace the battery per manufacturer's suggestion or at least every couple of years to prevent the controller from going into its default setting, which may turn the system on on the wrong day or at the wrong time. This could result in a fine. Once each zone is properly calibrated and set, don't change how long you water, just change how often according to actual need. If your controller has a "percent" setting, which adjusts the run time up or down for all zones, leave it permanently at $100 \%$. For additional resources on setting the irrigation controller, see "Operation of Residential Irrigation Controllers" (IFAS Publication CIR1421). 


\section{Rain Sensor Switch}

Be sure a rain sensor switch (Figure 4) accompanies your controller. It is purchased and installed as a separate, additional item. They are inexpensive, can save a lot of water and are required by Florida law since 1991 on new installations. Positioned with a clear view of the open sky and connected into the controller's wiring, the rain sensor switch will automatically prevent unnecessary watering when it's raining. A rain sensor switch will interrupt scheduled irrigation based on how much rainfall has occurred and will keep the system off for a preset "dry down" time. This is especially helpful for absentee homeowners who leave irrigation controllers in the "automatic" setting. But to be effective, the sensor must be adjusted and maintained. Adjust the switch to stop operation at 1/2 inch of rainfall and adjust the "dry down" vent to prevent a relatively short reactivation time. Your sensor's instruction sheet will give details on how to make the adjustments. Check it for proper operation monthly in the summer and quarterly the rest of the year. A simple method for checking is to pour or spray a small amount of water over the rain sensor while the irrigation system is operating. All zones should stop soon and remain off for at least a couple of days. The controller panel may appear to operate normally in spite of the overriding action of the rain sensor switch. Some controllers have a corresponding "on - off" rain switch control on the panel. On these models, the control should be set to activate the rain sensor. For further information see "Residential Irrigation System Rainfall Shutoff Devices" (IFAS Publication ABE 325).

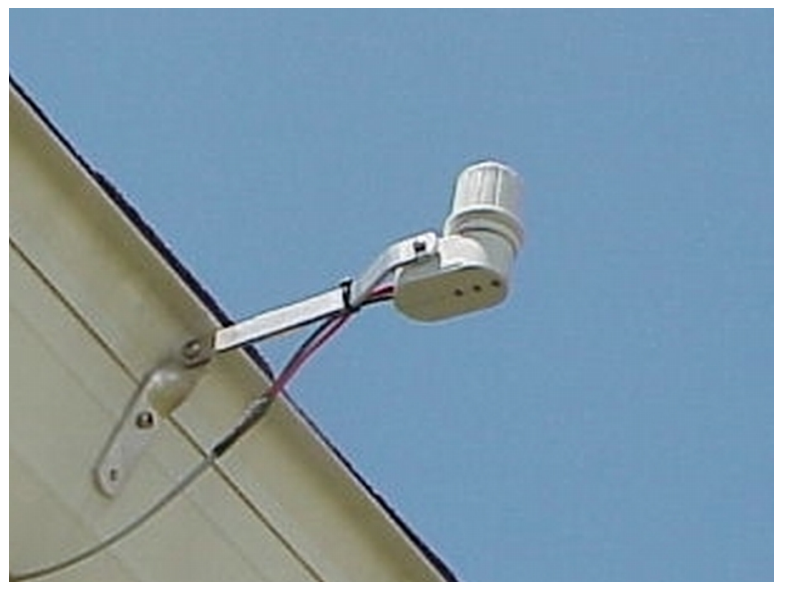

Figure 4. Rain Sensor Switch

\section{Conclusion}

Every lawn and landscape is different. By learning and practicing the basic principle of watering only as needed, you can have a beautiful, healthy lawn with less water. Taking control of the automatic sprinkler system is the first big step. Additional steps to reduce landscape water use include:

- Run the system at least twice a year during the daytime to inspect for leaks, proper head alignment and blocked sprinkler patterns.

- Repair broken piping and sprinklers to eliminate leaks.

- Adjust or reposition sprinklers to eliminate overspray on drives, walks, buildings, and into other irrigation zones.

- Don't mix sprinkler types (sprayers, rotors and micro) in a zone.

- Install sprinklers with head-to-head spacing and with matched precipitation rate nozzles for uniform water application.

- Expand the use of drought-tolerant shrubs in mulched beds.

- Separately water grass zones (more water) and shrub zones (less water).

- Use micro-irrigation on shrub and flowerbeds.

- Mow grass high and with a sharp blade.

- Make sure your rain sensor switch is properly installed and is operational.

About half the water used in homes today is for irrigation. Adopt these principles at your home for savings in both your utility bills and Florida's water resources. Contact your local county extension service and WMD for help.

\section{Referenced Publications}

- IFAS publication CIR1421 "Operation of Residential Irrigation Controllers" 
- IFAS publication ABE 325 "Residential

Irrigation System Rainfall Shutoff Devices"

- IFAS publication ENH70 “Coping With

Drought in the Landscape"

- IFAS publication ENH9 "Watering Your

Florida Lawn"

- Southwest Florida Water Management District publication "Saving Water Outdoors" 